\title{
AOR
}

Selected Papers of \#AoIR2021:

The 22nd Annual Conference of the Association of Internet Researchers Virtual Event / 13-16 Oct 2021

\section{MATCHING DIGITAL INTERVENTION AFFORDANCES WITH TASKS: THE CASE OF ZOOM AND WHATSAPP MENTAL HEALTH INTERVENTION FOR SENIORS DURING THE COVID-19 PANDEMIC}

\author{
Daphna Yeshua-Katz \\ Ben-Gurion University of the Negev \\ Stav Shapira \\ Ben-Gurion University of the Negev \\ Limor Aharonson-Daniel \\ Ben-Gurion University of the Negev
}

\author{
A. Mark Clarfield \\ Ben-Gurion University of the Negev, McGill University \\ Orly Sarid \\ Ben-Gurion University of the Negev
}

\section{Background}

During the first COVID-19 wave, we conducted a Zoom and WhatsApp digital group intervention that promoted community-dwelling older individuals' mental health. Following the intervention's implementation, in this study we placed the intervention in the context of media richness theory (MRT) (Daft \& Lengel, 1986; Rice, 1992) and affordances framework (Evans et al., 2017; Gibson, 1977; Rains, 2018) to explore the roles of the technological affordances and constraints of the video-conferencing app Zoom and the instant-messaging app WhatsApp in the intervention performance.

Media richness theory (MRT) is a framework used to describe a communication medium's ability to reproduce the information sent over it (Daft \& Lengel, 1986; Rice, 1992). Communication transactions that can clarify ambiguous issues to enhance understanding promptly are considered information-rich. Communication transactions that require a long time to enable understanding or that cannot overcome different

Suggested Citation (APA): Yeshua-Katz, D. Shapira, S. Aharonson-Daniel, L. Clarfield, A. M., Sarid, O. (2021, October). Matching digital intervention affordances with tasks: The case of Zoom and WhatsApp mental health intervention for seniors during the COVID-19 pandemic. Paper presented at AoIR 2021: The 22nd Annual Conference of the Association of Internet Researchers. Virtual Event: AolR. Retrieved from http://spir.aoir.org. 
perspectives are lower in richness or are information lean. Central to MRT is the proposition that tasks vary with respect to specific characteristics. Perrow (1967) originally proposed and described task analyzability as a basic task characteristic. Task analyzability refers to the way that individuals can respond to problems that arise in the process of task completion. Analyzable tasks are those for which predetermined responses to potential issues, and well-known procedures, are available and useful, because outcomes are well understood. In contrast, unanalyzable tasks require individuals to think about, create, or find satisfactory solutions to problems outside of the domain of facts, rules, or procedures (Rice, 1992).

We examined performance through the perspectives of the group moderators, technical support members, and principal investigators, and addressed the following research questions:

Research question 1: How did Zoom and WhatsApp affordances match (un)analyzable intervention tasks and contribute to the intervention performance? Research question 2: How did Zoom and WhatsApp constraints restrict (un)analyzable intervention tasks and hinder intervention performance?

Based on the media richness theory (MRT) and affordances approach, in this study we used netnography to explore how Zoom and WhatsApp technological affordances/constraints matched intervention tasks and increased intervention performance.

\section{Findings}

This section identifies four key Zoom and WhatsApp affordances - temporality, interactivity, multimediality, and portability - which we identified through observation during the intervention period and via moderators' perceptions. We examined these affordances in the context of MRT by examining the ways in which the 1) communication channel affordances matched the 2) intervention's (un)analyzable tasks to enhance the 3 ) intervention performance. See intervention's media richness assessment in Table 1. 
Table 1: Intervention's affordances and media richness assessment

\begin{tabular}{|c|c|c|c|c|}
\hline $\begin{array}{l}\text { Communication } \\
\text { channel }\end{array}$ & Media affordance & Task Characteristic & Feature used & Intervention performance \\
\hline Zoom & Temporality & Teaching techniques (UA) & Video chatting & $\begin{array}{l}\quad \text { Learning simple tasks } \\
\quad \text { Focused and ephemeral } \\
\text { communication }\end{array}$ \\
\hline WhatsApp & Temporality & $\begin{array}{l}\text { Scheduling meetings } \\
\text { Pre- and Post-measures of } \\
\text { well-being }(\mathrm{A})\end{array}$ & $\begin{array}{l}\text { Sending text } \\
\text { messages with links }\end{array}$ & $\begin{array}{ll}\checkmark & \text { Group management tool } \\
\therefore & \text { Ongoing communication } \\
\checkmark & \text { Socialization }\end{array}$ \\
\hline Zoom & Interactivity & $\begin{array}{l}\text { Building safe space \& } \\
\text { intimacy (UA) }\end{array}$ & $\begin{array}{l}\text { Gallery view } \\
\text { "Mute-all" }\end{array}$ & $\begin{array}{ll} & \text { Synch. communication } \\
\vee & \text { Connectedness } \\
\times & \text { Information load }\end{array}$ \\
\hline WhatsApp & Interactivity 수 & $\begin{array}{l}\text { Problem-solving (A and } \\
\text { UA) }\end{array}$ & $\begin{array}{l}\text { Text messages, link } \\
\text { sharing, \& WhatsApp } \\
\text { video calls }\end{array}$ & $\begin{array}{ll}\checkmark & \text { Emergency channel } \\
\checkmark & \text { Technical support } \\
\checkmark & \text { Socialization }\end{array}$ \\
\hline Zoom & Multimediality & Teaching techniques (UA) & Screen share & $\checkmark \quad$ Learning simple tasks \\
\hline WhatsApp & Multimediality & $\begin{array}{l}\text { Improve digital literacy } \\
\text { Teaching techniques (UA) }\end{array}$ & $\begin{array}{l}\text { Sharing image, audio, } \\
\text { \& video files }\end{array}$ & $\begin{array}{l}\checkmark \quad \begin{array}{l}\text { Conducting intervention in a } \\
\text { personal setting }\end{array} \\
\end{array}$ \\
\hline Zoom & Portability & Group interaction (UA) & $\begin{array}{l}\text { Small Screen size } \\
\text { Interface }\end{array}$ & $\begin{array}{ll}\times & \text { Limited presence } \\
\times & \text { Distress } \\
\times & \text { Physically demanding }\end{array}$ \\
\hline WhatsApp & Portability & $\begin{array}{l}\text { Practice techniques in safe } \\
\text { spaces (UA) }\end{array}$ & $\begin{array}{l}\text { Taking pictures \& } \\
\text { videos }\end{array}$ & $\begin{array}{l}\checkmark \text { Practicing techniques } \\
\text { individually } \\
\checkmark \text { Location independence }\end{array}$ \\
\hline
\end{tabular}

\section{Note:}

슬 = High; $=$ Low

$\mathrm{A}=$ Analyzable text; $\mathrm{UA}=$ Unanalyzable task

$\checkmark$ = Affords; $X=$ Constrains 


\section{Temporality}

Zoom and WhatsApp differed in their temporality, a term used to refer to how digital interaction over time is experienced by individual users, and how that influences the overall use pattern and experiences (Huang \& Stolterman, 2011). The moderators indicated the ways in which Zoom offered an ephemeral and focused window of time to deliver unanalyzable tasks such as leading group sessions. WhatsApp, for its part, helped maintain a co-presence that enhanced the unanalyzable task of social interaction and enabled moderators to support the Zoom meetings by stretching the interactions beyond specific meetings.

\section{Interactivity}

The second affordance that was important for delivering a remote intervention was interactivity, defined as the interaction-generating functions of the digital app's interface (Sundar, 2009), including the ability to comment, meta-voice, provide feedback, and engage (Evans et al., 2017). Zoom's rich media environment of video conferencing offers high interactivity, which enables the completion of unanalyzable tasks using synchronous communication between moderators and seniors, and among the seniors themselves. WhatsApp appears to offer an optimal solution for both analyzable and unanalyzable tasks supporting group and interpersonal interaction.

\section{Multimediality}

WhatsApp's and Zoom's multimediality, defined as the vast array of multimedia functions including voice and video calls, and the exchange of pictures, emojis, and audio and video messages (Schrock, 2015), enabled moderators and the research team's technical support people to take advantage of this information-rich media environment to reduce uncertainty and ambiguity during the intervention.

\section{Portability}

Out of all of the affordances we identified, the portability affordance of seniors' devices - defined as the ability to transport a device/app and to use it regardless of one's location (Schrock, 2015) - at times enabled but also constrained the unanalyzable task of creating group interaction by increasing uncertainty among the seniors and limiting their co-presence.

Empirically, our study identified specific affordances and constraints associated with the intervention. Theoretically, our study extends previous MRT work by expanding it with an affordance framework. In particular, our study approached MRT media characteristics through the affordances approach. It examined how the match between media affordance range (high vs. low) and intervention task (un)analyzability contributed to the intervention's performance. Hence, this study contributes to the field by deepening our understanding of how the variability of digital affordances (the range between low and high levels of temporality, interactivity, multimediality, and portability) might contribute to the performance of the intervention task. The match between the four affordances and task analyzability also provides a deeper understanding of 
affordance as a relational construct in the interplay between technological objects and outcomes. As such, this study lays the grounds for further testing the relation between affordance types and levels and task analyzability in future studies.

\section{References}

Daft, R. L., \& Lengel, R. H. (1986). Organizational Information Requirements, Media Richness and Structural Design. In Source: Management Science (Vol. 32, Issue 5). https://www.jstor.org/stable/2631846?seq=1\&cid=pdf-

Evans, S. K., Pearce, K. E., Vitak, J., \& Treem, J. W. (2017). Explicating Affordances: A Conceptual Framework for Understanding Affordances in Communication Research. Journal of Computer-Mediated Communication, 22(1), 35-52. https://doi.org/10.1111/jcc4.12180

Gibson, J. J. (1977). The theory of affordances. In Hilldale, USA (Issue 2).

Huang, C.-C., \& Stolterman, E. (2011). Temporality in Interaction Design. Proceedings of the 2011 Conference on Designing Pleasurable Products and Interfaces. https://doi.org/10.1145/2347504.2347572

Rains, S. A. (2018). Coping with Illness Digitally. The MIT Press. https://doi.org/10.7551/mitpress/11219.001.0001

Rice, R. E. (1992). Task Analyzability, Use of New Media, and Effectiveness: A MultiSite Exploration of Media Richness. Organization Science, 3(4), 475-500. https://doi.org/10.1287/orsc.3.4.475

Schrock, A. R. (2015). Communicative affordances of mobile media: Portability, availability, locatability, and multimediality. International Journal of Communication, 9(1), 1229-1246. https://ijoc.org/index.php/ijoc/article/view/3288

Sundar, S. S. (2009). Media effects 2.0: Social and psychological effects of communication technologies. In R. L. Nabi \& M. B. Oliver (Eds.), The SAGE Handbook of Media Processes and Effects (pp. 545-560). SAGE Publications. https://books.google.co.il/books?id=NmpHjF-XU5AC 